\title{
An evaluation of persistent meteorological drought using a homogeneous Island of Ireland precipitation network
}

\author{
R. L. Wilby, ${ }^{a *}$ S. Noone, ${ }^{\mathrm{b}}$ C. Murphy, ${ }^{\mathrm{b}}$ T. Matthews, ${ }^{\mathrm{c}}$ S. Harrigan ${ }^{\mathrm{b}}$ and C. Broderick ${ }^{\mathrm{b}}$ \\ ${ }^{a}$ Department of Geography, Loughborough University, UK \\ ${ }^{\mathrm{b}}$ Department of Geography, National University of Ireland Maynooth, Ireland \\ c School of Natural Sciences \& Psychology, Liverpool John Moores University, UK
}

\begin{abstract}
This paper investigates the spatial and temporal properties of persistent meteorological droughts using the homogeneous Island of Ireland Precipitation (IIP) network. Relative to a 1961-1990 baseline period it is shown that the longest observed run of below average precipitation since the 1850s lasted up to 5 years (10 half-year seasons) at sites in southeast and east Ireland, or 3 years across the network as a whole. Dry spell and wet spell length distributions were represented by a first-order Markov model which yields realistic runs of below average rainfall for individual sites and IIP series. This model shows that there is relatively high likelihood $(p=0.125)$ of a 5-year dry spell at Dublin, and that near unbroken dry runs of 10 years or more are conceivable. We suggest that the IIP network and attendant rainfall deficit modelling provide credible data for stress testing water supply and drought plans under extreme conditions.
\end{abstract}

KEY WORDS drought duration; homogeneous rainfall series; Ireland; Markov model; water planning

Received 13 July 2015; Revised 2 September 2015; Accepted 4 September 2015

\section{Introduction}

Drought is hardly synonymous with perceptions about the climate of Ireland. Nonetheless, the Freeman's Journal provides numerous reports of potable water shortages in Dublin during severe dry spells over the period 1763-1924 and Barrington (1888) gives a rich account of impacts of the 1887 drought on Irish agriculture (Freeman's Journal available through Irish Newspaper Archives www.irishnewsarchive.com/). Other notable events such as the pan-European drought of 1976 caused heat- and moisture-stress-related problems for Ireland's agricultural sector (Stead, 2014). Similarly, some future climate scenarios foresee loss of production for crops such as potatoes linked to rising temperatures and summer aridity (Holden et al., 2003); reduced grass growth and heat stress on livestock which could impact meat and dairy exports (Hunt et al., 2014); and decreased river flow in summer (Steele-Dunne et al., 2008; Bastola et al., 2011).

Given these vulnerabilities, surprisingly little has been published on the drought climatology of Ireland. O'Laoghog (1979) provides a summary of rainfall anomalies alongside impacts on agriculture and public water supply of the 1974-1976 drought. Brogan and Cunnane (2005) contend that 1976 may have witnessed the lowest recorded river flows since the 1930s. They also cite droughts in 1934, 1949, 1955, 1959, 1975, 1989, 1990, 1991 and 1995. MacCarthaigh (1996) compared 1995

\footnotetext{
* Correspondence to: R. Wilby, Department of Geography, Loughborough University, Loughborough LE11 3TU, UK. E-mail: r.l.wilby@lboro.ac.uk
}

with droughts back to 1975 whilst Dooge (1985) provides a synopsis of droughts in Irish history beginning with accounts in the Annals of Ulster and of Clonmacnoise (for the period AD 759 to 1408). Symons (1887) documents five droughts in the 1850s, two in the 1860s and three in the 1870s. Garcia-Suarez and Butler (2006) find periods with persistently negative annual Palmer Drought Severity Index at Armagh in the 1880s, 1890s, 1930s, 1970s and 1990s. Mandal (2011) estimated low flows for 125 Irish rivers using catchment properties. Aside from these sources, there is little quantitative information on which to base rigorous assessments of long-term drought risk and water planning for Ireland.

The present research article addresses this knowledge gap by using the homogeneous Island of Ireland Precipitation (IIP) network of Noone et al. (2015) to evaluate the occurrence and persistence of meteorological droughts since 1850. Here, a straightforward definition of drought is used for half-year periods or longer that have below average precipitation, at both site and regional scales. We accept that the term 'drought' is ambiguous and that runs of seasonal rainfall deficiency do not necessarily translate into periods of agricultural, hydrological or environmental drought (Wilhite and Glantz, 1985). Nonetheless, our interrogation uses seasonal rainfall and persistence metrics not applied in the homogenization process to quality assure the integrity of series within the IIP network. We first reprise the methods used to homogenize the IIP series and list other homogeneous rainfall products for comparison. We then describe and apply statistical techniques for simulating occurrence and persistence of below average rainfall across the IIP network. This leads into an account 
and interpretation of the key findings before concluding with a few suggestions for further research.

\section{Data}

Our analysis draws on several data sets. The homogeneous IIP network contains monthly totals for 25 stations (Figure 1) covering the common years 1850 to 2010 (Noone et al., 2015). Precipitation data underpinning the IIP network were drawn from four sources: long-term series held by the Climatic Research Unit (UK) and Centre for Environmental Data Archival (UK) updated to 2010 (16 stations); the record of Armagh Observatory (UK) (1 station); plus digital and paper records of varying completeness held by Met Éireann (IE) (8 stations). Raw data exist for all 25 stations from 1908; 23 from the 1890s; 19 from the 1880s; and 8 in the 1850s. The longest continuous record is for Belfast which begins in 1812 .

In preparation of the IIP network, for each station, detailed information about correction factors, nearest neighbours, observer practices, meteorological site and gauge condition was transcribed to a master file of metadata to help interpret break points detected during homogenisation. The HOMegenisation softwarE in $\mathrm{R}$ (HOMER) package (Mestre et al., 2013) was used to detect and correct inhomogeneity in the monthly series and to infill/extend records to the period 1850-2010 (see: Noone et al., 2015). HOMER compares differences between candidate and reference sites within a network to identify probable break points that can then be ratified against metadata. Given the low density of long-term stations available for IIP, at least 12 correlated reference stations for each candidate series were identified for pairwise comparison and break detection. Annual correction factors were applied to confirmed break points using an analysis of variance (ANOVA) model (Caussinus and Mestre, 2004; Venema et al., 2012; Mestre et al., 2013). Missing data were infilled using the same method such that all records start in 1850 with correction factors based on the adjustment amplitude applied until the first detected change point of the series (Noone et al., 2015). Finally, the regional IIP series was constructed as the unweighted monthly mean of the 25 series.

Monthly precipitation totals for England and Wales (EWP), Scotland (SP) and Northern Ireland (NIP) were obtained from the Met Office Hadley Centre. The EWP series begins in 1766, whereas SP and NIP start in 1931. All series are based on long-running meteorological stations weighted to provide spatially and temporally homogeneous, area-averaged precipitation totals (Alexander and Jones, 2001). These precipitation series were used alongside the metadata and archival material described above to quality check the provenance of the IIP series and major dry spells detected therein.

\section{Methods}

Following Wilby et al. (2015) the homogeneous IIP series were processed in four ways. First, mean monthly precipitation totals were derived for a baseline period 1961-1990 with averages consolidated into mean winter (October to March) and summer (April to September) half years. Seasonal anomalies were then calculated for the 1850-2010 series relative to 1961-1990 half-year means, recognizing that spell lengths are sensitive to choice of baseline period (Sen, 1980). As will be shown later, 1961-1990 was a relatively dry period. Therefore, any negative anomalies referenced to this baseline are indeed noteworthy.

The number of stations with below average precipitation was counted for each half year to establish the spatial coherence of dry spells, accepting that this is a crude metric because of the sparse and uneven distribution of sites (Figure 1). When more than two thirds of stations in the IIP network report a dry season the event is regarded as widespread and unlikely to be due to a local anomaly or suspect data. Dates of spells lasting three or more half-year seasons were then cross-referenced to EWP and SP to establish coherence at the scale of the British-Irish Isles.

Second, conditional dry-to-dry (Pdd) and wet-to-wet (Pww) first-order Markov model transition probabilities were determined from series of seasonal anomalies. This involved counting the frequency with which a below average season is followed by another dry season. Pdd is the proportion of transitions that are dry-to-dry out of all transitions (i.e. dry-to-dry plus dry-to-wet). Similarly, Pww was derived from the proportion of wet-to-wet transitions. Unbroken dry season and wet season runs were used to construct frequency distributions of spell lengths and to identify the most persistent dry spells in each record. Pdd and Pww were also estimated for 30-year moving blocks to establish whether there has been any long-term change in dry spell and/or wet spell persistence throughout the IIP, EWP, NIP and SP series.

Third, as in Wilby (2007), Sharma and Panu (2012, 2014a, 2014b) and Wilby et al. (2015), Pdd and Pww transition probabilities based on 1850-2010 observations were used to stochastically simulate series of seasons with above or below average rainfall. The process begins by seeding with a uniform random number $r[0,1]$ to determine whether there is a change from the initial state (assumed to be below average rainfall). If $r \leq$ Pdd the dry spell continues; if $r>$ Pdd then the new state is wet and Pww is applied at the next time step. In this way, a single 10000 season Markov model simulation was performed to generate a distribution of synthetic spell lengths. The two-sample, non-parametric Kolmogorov-Smirnov (KS) test was applied to determine whether the largest discrepancy (Dstat) between observed and simulated cumulative distributions of spell-length was significantly $(p<0.05)$ greater than expected by chance.

Finally, 1000 boot-strap, Markov model simulations were performed to generate 100- and 160-year (i.e. 200 and 320 season) sequences for each site and region. Maximum dry spell and wet spell lengths were retained from all 1000 realizations to construct distributions of synthetic 100- and 160-year spells for comparison with observations. The 160-year event was generated for equivalence 


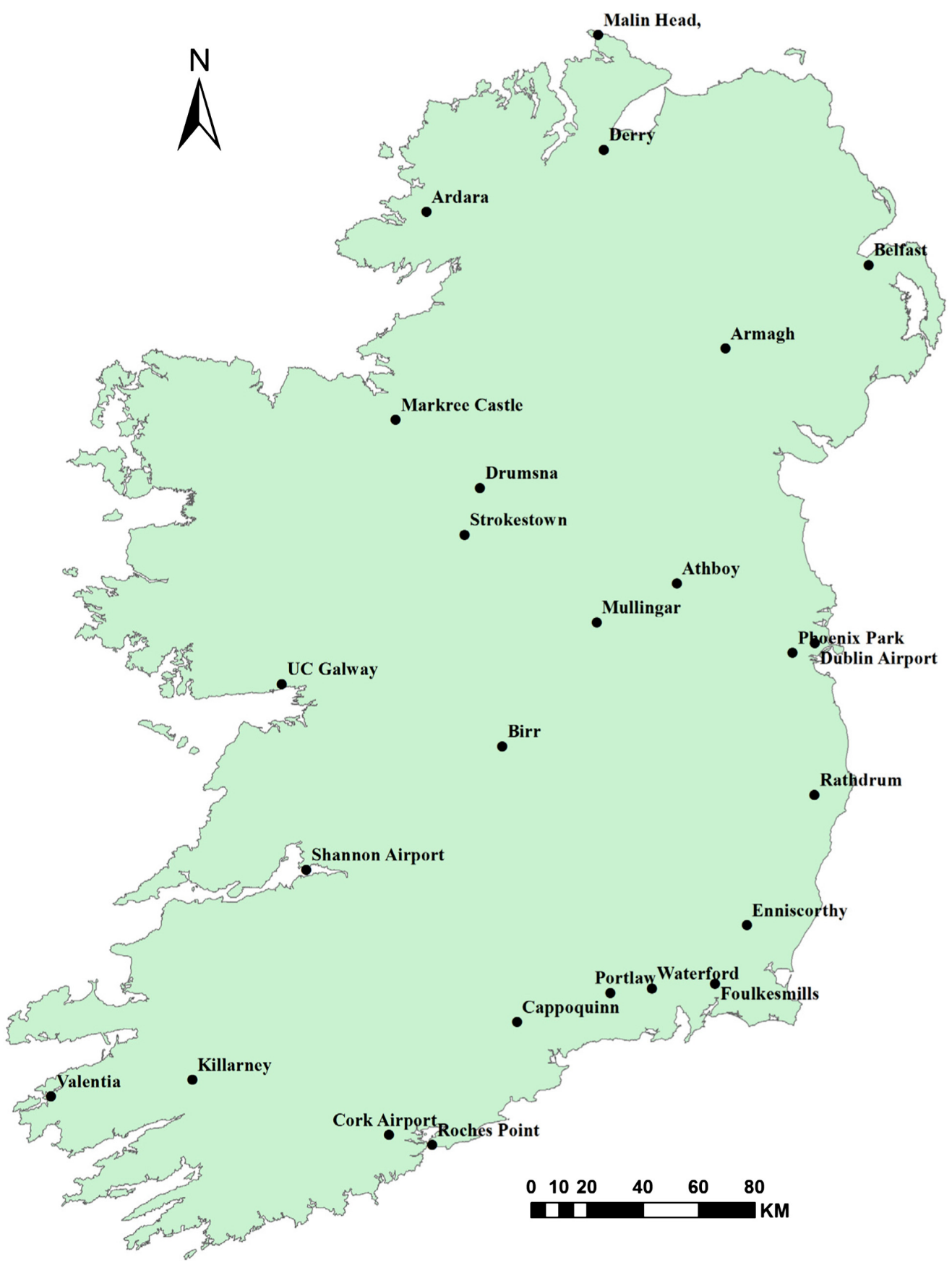

Figure 1. Map of station locations.

with observed record lengths; the 100-year event enables comparison with Wilby et al. (2015). Both sets of distributions were used to estimate likelihoods of a 10-season spell with below average precipitation at each site. This provides an upper bound (yet plausible) dry spell that is much longer than the single season (1995) design drought applied in, for example, the Dublin City Council (2010) Water Plan.

\section{Results}

Figure 2 shows seasonal anomalies as percentages of the 1961-1990 mean for IIP and EWP since 1850. The
IIP series is significantly correlated with both EWP $(r=+0.75)$ and SP $(r=+0.57)$ (not shown). Seasonal anomalies of IIP vary between $-40 \%$ (winter 1879/80) and $+49 \%$ (summer 1924). Most (84\%) seasons lie within $\pm 20 \%$ of the 1961-1990 average precipitation. Overall, the driest 30-year period in IIP was 1884-1913 with 2\% less precipitation than 1961-1990. Hence, our chosen standard period was close to the very driest continuous run in the IIP series and any negative anomalies would certainly have been indicative of dry seasons. However, as noted at the outset, meteorological droughts do not necessarily coincide with significant agricultural, water resource or environmental stress. 


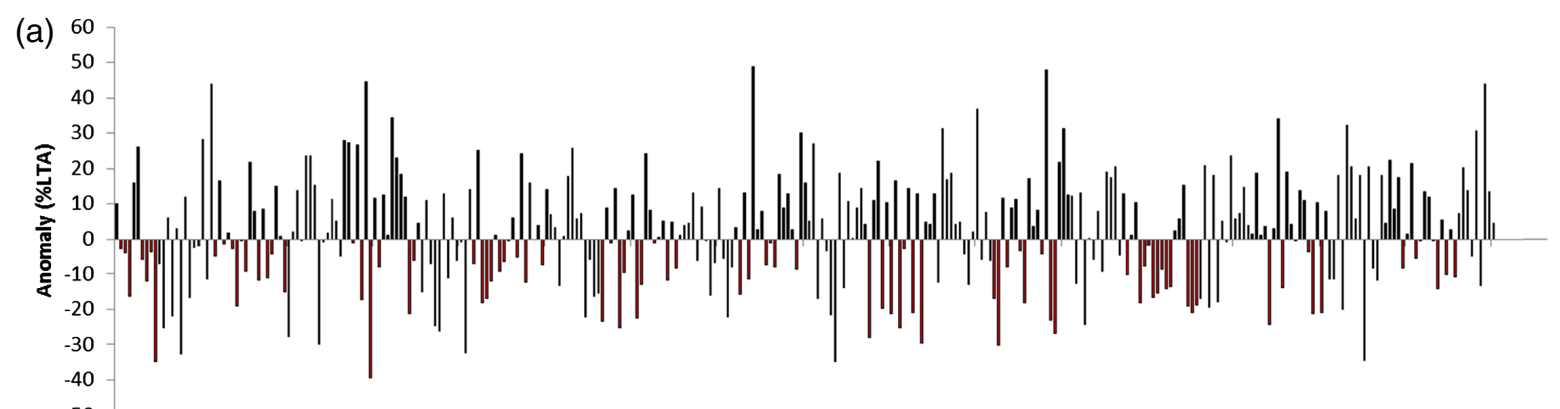

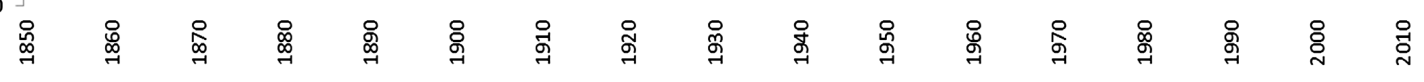

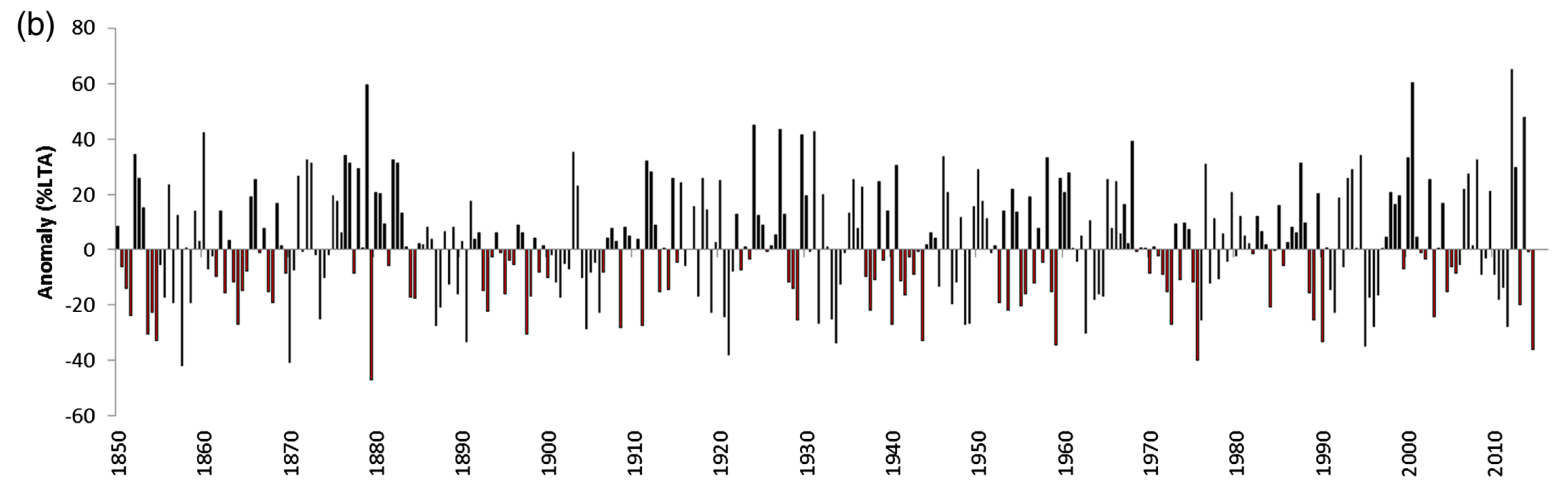

Figure 2. Above and below long-term average precipitation totals in winter (October to March) and summer (April to September) half years (seasons) across a) the Island of Ireland and b) England and Wales for the years 1850-2010. All deviations are percentage anomalies with respect to the 1961-1990 mean.

Nine dry spells lasting longer than three seasons (and simultaneously occurring at more than two thirds of stations) were identified (Table 1). Persistent events stand out in 1853-1856, 1886-1888 (followed shortly by 1892-1894) and 1970-1973 (tailed by 1974-1976). Dry spells in the 1850s and late 19th century have been reported previously for Ireland (Symons, 1887; Barrington, 1888; Tabony, 1980) and for England and Wales (Barker et al., 2004; Jones et al., 2006; Burt and Horton, 2007; Marsh et al., 2007; Burt and Howden, 2011; Wilby and Quinn, 2013). Similarly, dry spells in the 1970s achieved notoriety for their drought orders, rota cuts and standpipes across parts of south Wales, central and southern England, water rationing in the Channel Islands, and even nightly shut-offs in Belfast (Rodda and Marsh, 2011). Another noteworthy feature is the relatively quiet period 1908-1950 for widespread, multi-year droughts (Table 1). Our criteria (i.e. two thirds of stations reporting anomalies lasting at least three seasons) exclude well-known intense, but short-lived droughts of 1921, 1933/1934 and 1941-1943 that are evident in both IIP and EWP (Marsh et al., 2007).

Overall, the longest unbroken runs of dry half-years in IIP were 14 seasons at Waterford (1912-1919/1920); 12 at Cork Airport (1905-1911); 11 at both Markree Castle (1882-1887/1888) and Mullingar (1904-1909) (Figure 3). All four dry spells occurred prior to the era of digital records (1941) but overlap with the coherent rainfall deficits (Table 1) of 1886-1888 (at Markree Castle) and 1905-1907 (at Cork Airport and Mullingar). While no
Table 1. Periods with more than $2 / 3$ of all IIP stations reporting below average seasonal rainfall for at least three continuous seasons compared with dry spell lengths in IIP, EWP and SP. Note that NIP was not included because of the risk of double-counting with IIP.

\begin{tabular}{lccc}
\hline Period & \multicolumn{3}{c}{ Number of seasons } \\
\cline { 2 - 4 } & IIP & EWP & SP \\
\hline $1853-1856$ & 6 & 5 & - \\
$1858-1860$ & 3 & 1 & - \\
$1886-1888$ & 3 & 2 & - \\
$1892-1894$ & 3 & 3 & - \\
$1905-1907$ & 3 & 3 & - \\
$1951-1953$ & 3 & 2 & 2 \\
$1962-1964$ & 3 & 3 & 5 \\
$1970-1973$ & 5 & 4 & 3 \\
$1974-1976$ & 4 & 3 & \\
\hline
\end{tabular}

breaks in this period were detected by Noone et al. (2015) the exceptionally long run of seasons with below average precipitation at Waterford may be explained in part by documented movements and sheltering of the rain gauge at Gortmore (used to bridge the record by Tabony (1980)). Metadata further signal that the Markree Castle gauge was 'leaking' and the provenance of a 10 season dry spell at Belfast is questionable due to a large change of correction factor applied by Tabony (1980) for bridging stations in the $1850 \mathrm{~s}$.

The most persistent dry spell recorded anywhere in the IIP network since record digitization (1941) lasted 

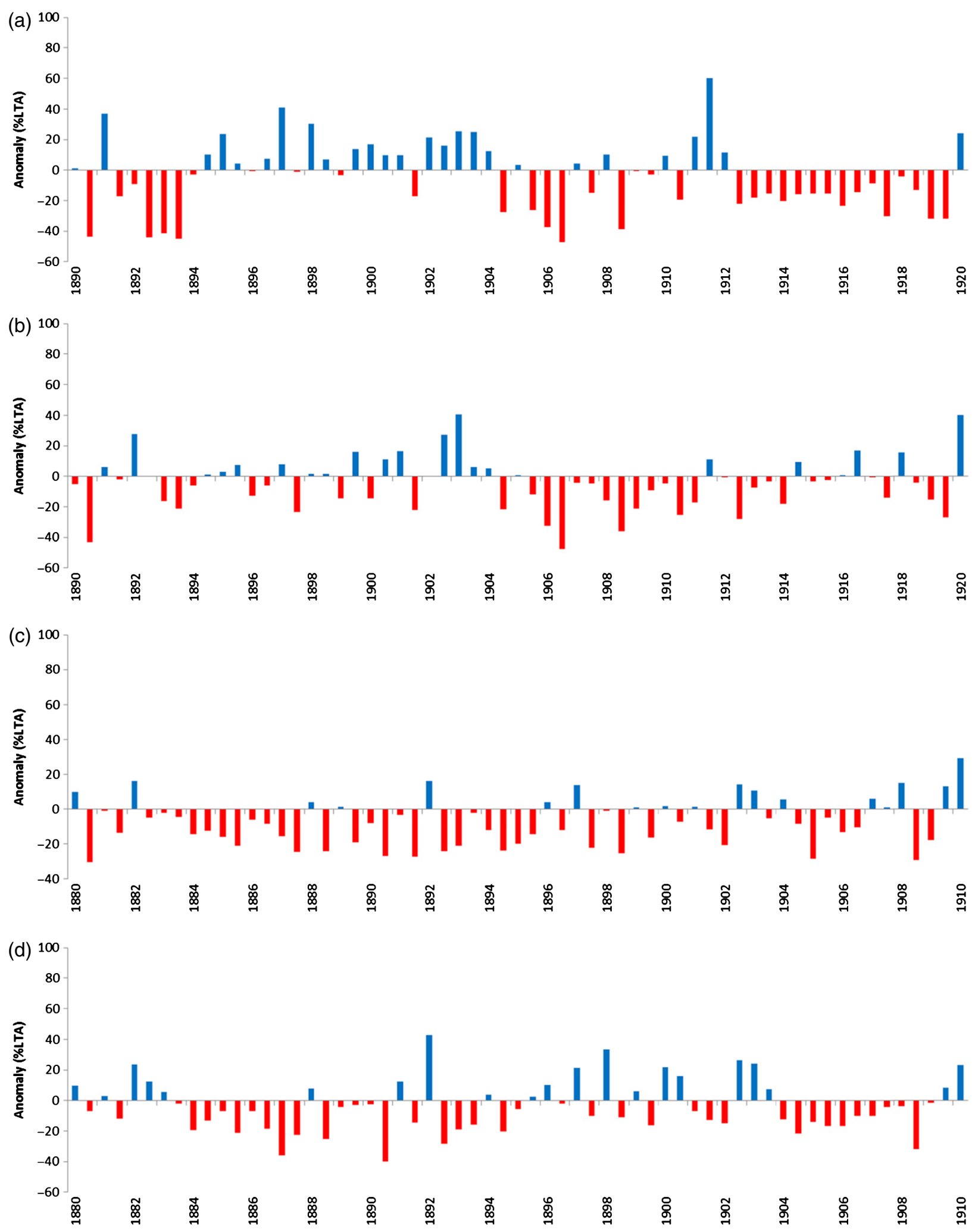

Figure 3. Long-run dry spells at (a) Waterford (1912-1919/1920), (b) Cork Airport (1905-1911), (c) Markree Castle (1882-1887/1888) and (d) Mullingar (1904-1909).

nine seasons at Cappoquin (1969-1973). This period partially overlaps with the longest dry runs in the central and southeast part of the network covering Athboy, Birr Castle, Drumsna, Enniscorthy, Foulkesmills, Portlaw and Roches Point (Table 2). The single season drought in 1995 is noteworthy for the large precipitation anomaly $(-35 \%)$ averaged across all stations in the IIP network. The most recent 20 years have witnessed only a few single and two season dry spells (in 1996-1997, 2001-2002 and 2003-2004) consistent with wetter and 
Table 2. Observed maximum dry spell duration (seasons) compared with simulated mean 160- and 100-year events at each site as well as for IIP, NIP, EWP and SP. Likelihoods of a simulated 10-season dry spell are also given.

\begin{tabular}{|c|c|c|c|c|c|c|}
\hline \multirow[t]{2}{*}{ Record } & \multicolumn{2}{|c|}{ Observed maximum event } & \multicolumn{2}{|c|}{ Simulated 160-year event } & \multicolumn{2}{|c|}{ Simulated 100-year even } \\
\hline & Period(s) & $\begin{array}{l}\text { Length } \\
\text { (seasons) }\end{array}$ & $\begin{array}{l}\text { Length } \\
\text { (seasons) }\end{array}$ & $\begin{array}{l}\text { Likelihood } \\
\text { (10 season) }\end{array}$ & $\begin{array}{l}\text { Length } \\
\text { (seasons) }\end{array}$ & $\begin{array}{l}\text { Likelihood } \\
\text { (10 season) }\end{array}$ \\
\hline Ardara & $1927-1932$ & 9 & 6.7 & 0.028 & 6.1 & 0.017 \\
\hline Armagh & $1892-1895$ & 7 & 5.5 & 0.008 & 5.1 & 0.002 \\
\hline Athboy & $1969-1973$ & 8 & 7.0 & 0.044 & 6.4 & 0.027 \\
\hline Belfast & $1853-1858$ & 10 & 7.4 & 0.058 & 6.6 & 0.029 \\
\hline Birr Castle & $1970-1973$ & 5 & 5.2 & 0.005 & 4.7 & 0.001 \\
\hline Cappoquin & $1969-1973$ & 9 & 6.4 & 0.021 & 5.8 & 0.015 \\
\hline Cork Airport & $1905-1911$ & 12 & 7.8 & 0.086 & 7.1 & 0.045 \\
\hline Derry & $1885-1988$ & 6 & 6.3 & 0.022 & 5.7 & 0.014 \\
\hline Drumsna & $1966-1970$ & 7 & 6.6 & 0.024 & 6.0 & 0.018 \\
\hline Dublin Airport & $1903-1907$ & 8 & 8.7 & 0.125 & 7.8 & 0.069 \\
\hline Enniscorthy & $1969-1973$ & 8 & 7.8 & 0.068 & 7.0 & 0.057 \\
\hline Foulkesmills & $1969-1973$ & 8 & 5.6 & 0.008 & 5.2 & 0.001 \\
\hline Killarney & $1853-1856,1939-1942$ & 6 & 5.8 & 0.010 & 5.2 & 0.005 \\
\hline Malin Head & $1950-1954$ & 7 & 6.9 & 0.033 & 6.3 & 0.022 \\
\hline Markree Castle & $1882-1988$ & 11 & 8.6 & 0.127 & 7.9 & 0.089 \\
\hline Mullingar & $1904-1909$ & 11 & 8.0 & 0.111 & 7.3 & 0.065 \\
\hline Phoenix Park & $1903-1908$ & 9 & 7.9 & 0.070 & 7.2 & 0.053 \\
\hline Portlaw & $\begin{array}{l}1855-1958,1888-1991 \\
1904-1907,1948-1950 \\
1969-1971,2003-2006\end{array}$ & 5 & 7.6 & 0.067 & 7.0 & 0.046 \\
\hline Rathdrum & $1853-1856$ & 6 & 6.3 & 0.017 & 5.8 & 0.015 \\
\hline Roches Point & $\begin{array}{l}1941-1943,1961-1963 \\
1969-1971,1974-1976 \\
1990-1992\end{array}$ & 4 & 5.7 & 0.009 & 5.2 & 0.008 \\
\hline Shannon Airport & $1904-1907$ & 6 & 6.8 & 0.032 & 6.2 & 0.018 \\
\hline Strokestown & $1919-1922$ & 9 & 6.2 & 0.027 & 5.8 & 0.008 \\
\hline UC Galway & $1887-1891$ & 7 & 7.2 & 0.048 & 6.6 & 0.033 \\
\hline Valentia & $1908-1911,1970-1973$ & 6 & 6.6 & 0.023 & 6.0 & 0.021 \\
\hline Waterford & $1912-1920$ & 14 & 7.5 & 0.061 & 6.9 & 0.048 \\
\hline IIP & $1969-1973$ & 8 & 6.0 & 0.012 & 5.6 & 0.009 \\
\hline NIP & $1970-1973$ & 7 & 6.0 & 0.014 & 5.5 & 0.009 \\
\hline EWP & $\begin{array}{l}1900-1903,1904-1907 \\
1941-1944\end{array}$ & 8 & 7.0 & 0.044 & 6.5 & 0.034 \\
\hline SP & $1970-1973$ & 6 & 5.6 & 0.008 & 5.0 & 0.004 \\
\hline
\end{tabular}

stormier conditions (Sutton and Dong, 2012; Matthews et al., 2014, 2015).

The relative quiescence of droughts since the 1990s is reflected by the moving average Pdd and Pww indices (Figure 4). In particular, Pww shows non-stationary behaviour towards more persistent wet spells that is also evidenced by the EWP and SP series. The 30-year mean Pww for IIP peaked in 2009 whereas Pdd is now lower than at any time since the period 1938-1967, consistent with trends in SP (note that IIP and NIP are not independent series because the former contains some records used to construct the latter. With this in mind, the divergence in persistence behaviours over the last decade could reflect the influence of the comparatively high density of stations within IIP along the east and southeast seaboard).

The KS test indicates that simulated and observed spell distributions are statistically $(p<0.05)$ indistinguishable across all regional (Figure 5) and station (Figure 6) series. The model tends to overstate the frequency of single-season dry spells and underestimate the occurrence of two-season events. Overall, the geometric distribution yielded by the Markov model provides good representations of the observed dry spell length distribution. The closest match for dry spells is for Shannon airport $(\mathrm{KS}=0.017)$ and greatest discrepancy for Ardara $(K S=0.111)$. Note, however, that the KS results are for the whole distribution whereas the fit to tails is more relevant for estimating low frequency events. Validation data are limited for this part of the distribution therefore we are restricted to assessing the ability of the model to generate the maximum observed dry spell length at each site.

Table 2 shows the extent to which bootstrap Markov model simulations replicate the most extreme runs of dry spells in the 160-year series. The model overestimates the duration of the 160-year dry spell by less than one season at seven sites and by more than one season at two sites. The largest discrepancy is for Portlaw where the model simulates a 7.6 season dry spell compared with five season run in observations. Metadata suggest that some precipitation totals are too high at this site due to incorrect conversion between inches and $\mathrm{mm}$. Conversely, 

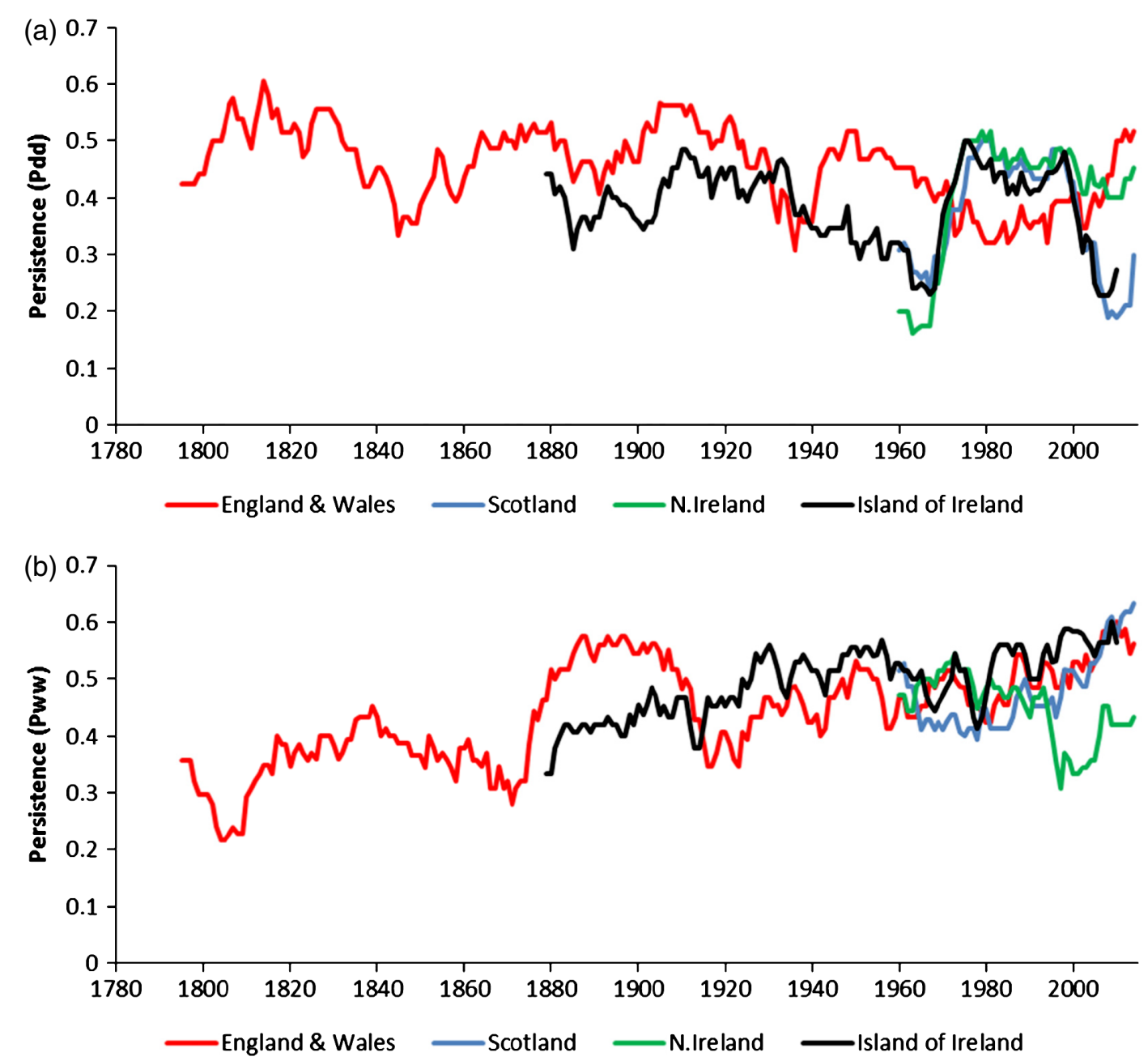

Figure 4. (a) Dry-to-dry (Pdd) and (b) wet-to-wet (Pww) season persistence for the Island of Ireland, Northern Ireland, England and Wales, and Scotland. All series are based on 30-year moving windows with anomalies referenced to the 1961-1990 mean. Source: Wilby et al. (2015).

the maximum observed dry spell is underestimated by less than one season at 5 sites and more than one season at 13 sites. The largest difference is at Waterford with 14 observed and 7.5 simulated seasons. As noted above, this mismatch may be explained by the probable under-catch and site changes affecting the Waterford record.

The 160- and 100-year simulations also provide likelihoods for a 10-season dry spell for each site and region (Table 2). This outcome is over three times more probably across EWP $(p=0.044)$ than for IIP $(p=0.012)$. To date, the maximum observed dry spell for Dublin is eight seasons (1903-1907); however, the Markov model suggests a relatively high likelihood ( $p=0.125$ ) of a 10-season run of rainfall deficiencies in a 160-year record. A slightly higher likelihood is estimated for Markree Castle $(p=0.127)$ but this could be due to fitting the model to a record with possible rainfall under-catch in the early part of the series. On the other hand, a 10-season dry-run is least likely at Armagh $(p=0.008)$, Birr Castle $(p=0.005)$, Foulkesmills $(p=0.008)$ and Roches Point $(p=0.009)$.

Comparison of probability distributions for simulated maximum dry spell and wet spell lengths reveals three distinct patterns (Figure 7). There are sites with greater dry spell persistence than wet spell persistence (Dublin, Enniscorthy, Markree Castle, Mullingar, Phoenix Park); sites where wet spell and dry spell lengths have similar likelihoods (Ardara, Athboy, Belfast, Cork, Derry, Drumsna, Malin Head, Portlaw, Rathdrum, Strokestown, UC Galway, Waterford); and sites where a given wet spell length is more likely than the same length dry spell (Armagh, Birr, Cappoquinn, Foulkesmills, Killarney, Roches Point, Shannon, Valentia). Across all sites and 100-year simulations, the longest dry spell was generated for Dublin and persisted 24 seasons (not shown in Figure 7). This might appear implausible but Dublin observations contain near unbroken runs exceeding 20 seasons in 1850-1868 (26/36), 1928-1946 (23/36) and 1961-1978 (23/35).

\section{Discussion}

Using 1961-1990 as the reference period (and excluding Waterford and Markree Castle for reasons noted above) we found that the longest observed run of below average precipitation persisted 12 seasons at Cork Airport (1905-1911). Noone et al. (2015) note that this record was originally constructed by Tabony (1980) using a composite 

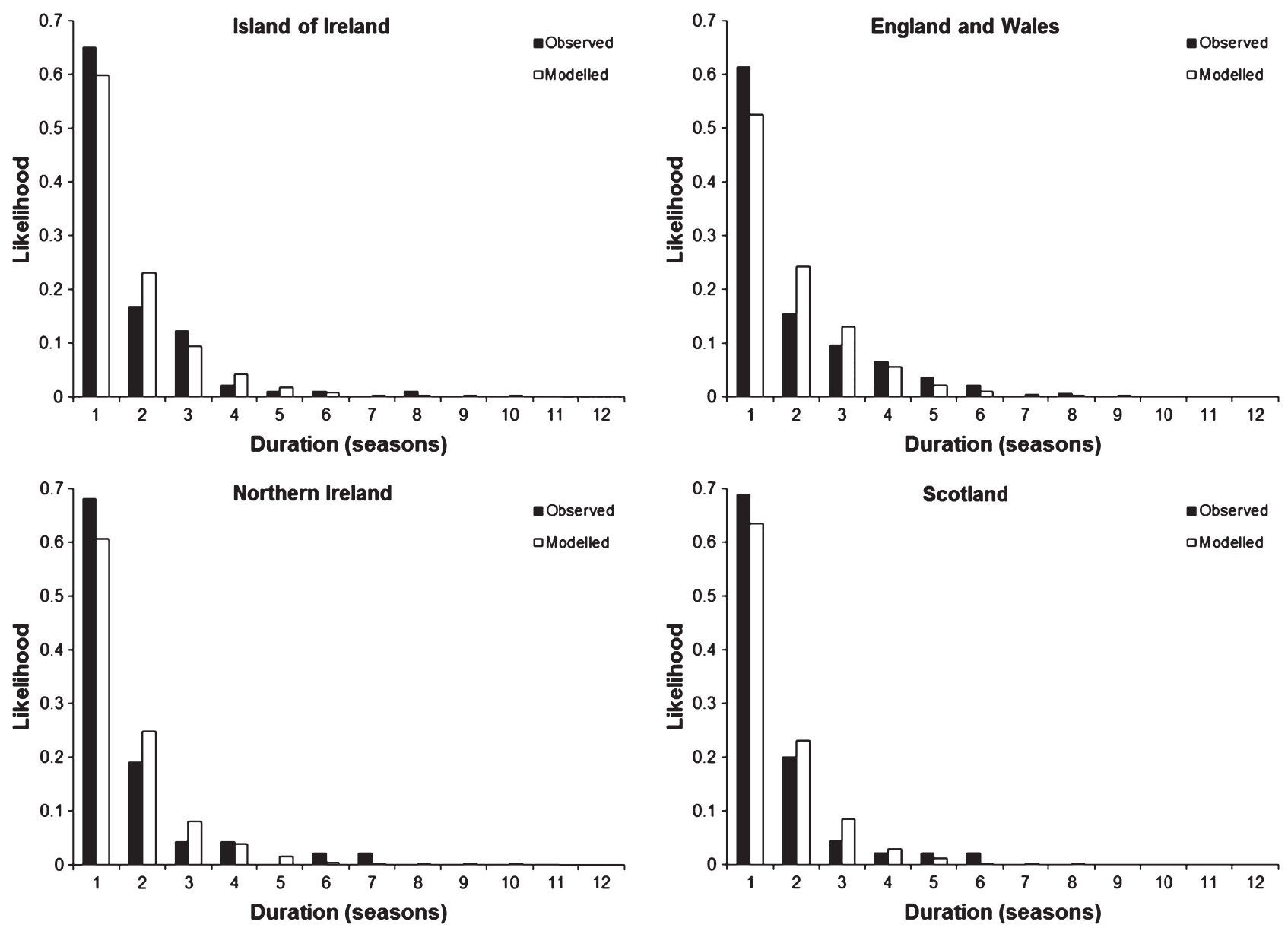

Figure 5. Observed and modelled likelihood of dry spells of duration 1-12 seasons in the Island of Ireland (1850-2010), Northern Ireland (1931-2014), England and Wales (1766-2014) and Scotland (1931-2014). Source: Wilby et al. (2015).

of stations with data prior to 1962 based on a lower elevation gauge at University College Cork. This station change is thought to explain lower early seasonal totals and a detected break point in 1958. The break was adjusted by Noone et al. (2015) but the same correction factor was applied across all months which could affect dry run persistence for this station.

The next longest run lasted 11 seasons at Mullingar (1904-1909) but, again, Noone et al. (2015) report break points in 1937 and 1950 that could be due to a station change in the latter case. Correction of the 1950 break resulted in a large downward adjustment, again potentially affecting dry run persistence. The 10 season dry spell at Belfast (1853-1858) has already been queried, so the longest run now becomes nine seasons at Ardara (1927-1932), Cappoquinn (1969-1973), Phoenix Park (1903-1908) and Strokestown (1919-1912) (Table 2). The Ardara record is based on a composite of stations with a small amplitude break point in 1983. While Strokestown has been bridged from 1961, the years 1908-1961 represent a stable period in the record (Noone et al., 2015). No breaks were detected for Cappoquinn and there are no issues of note from metadata. There are documented station moves early in the record at Phoenix Park but these pre-date the identified dry run and a station inspection in 1903 noted a very clear/open site. Therefore, having accounted for break points, station/instrument changes and reported measurement errors the most credible, conservative upper bound continuous dry spell length for the IIP network is nine seasons.

Our sub-annual analysis interrogated data that were homogenized at annual scales and thus represents a stringent test of the IIP network. Anecdotal accounts, proxy sources and data from neighbouring regions, all provide a basis for quality assuring our catalogue of widespread multi-year rainfall deficits (Table 1). We find issues with two stations (Waterford and Markree Castle) that were not picked up in the annual homogenisation of Noone et al. (2015). While the confounding issues identified by metadata may have negligible effect at annual resolution they can evidently become important when examining long duration rainfall deficits. In addition, suspicion is raised at Cork, Mullingar and Belfast that high persistence of negative rainfall anomalies may be an artefact of using a single correction factor equally across several months. Both issues arise despite application of best-practice methods for homogenisation and emphasize the need for cautious use of homogenous series, particularly when examining sequences of sub-annual extremes (note that snowfall is only a small component of total precipitation across 

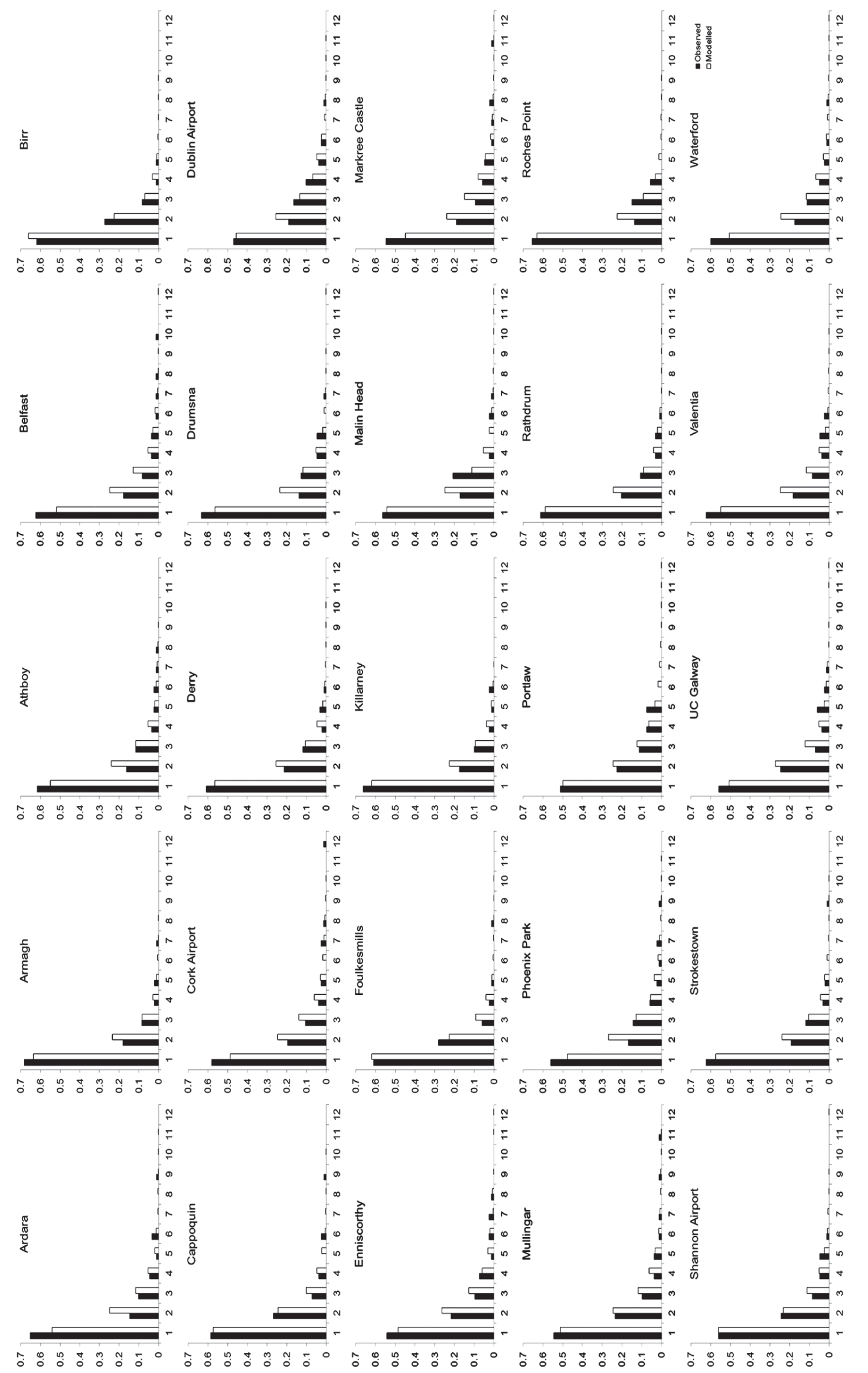

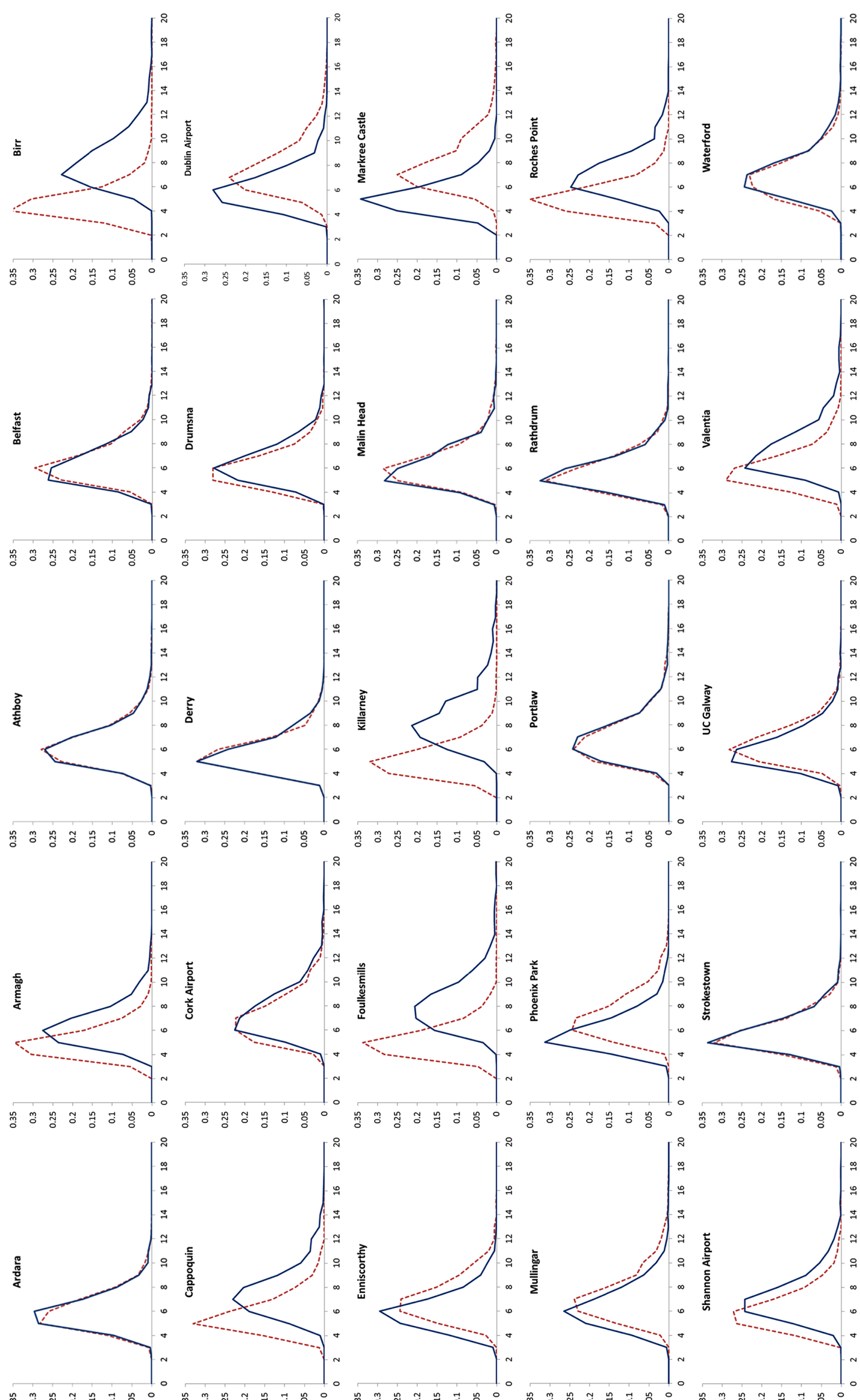

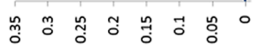

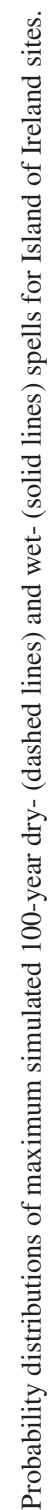

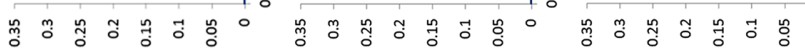

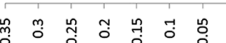

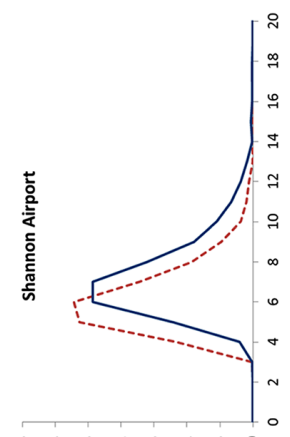

혼 
Ireland and thus any underestimation normally associated with snowy climates is a minor concern). Our analysis shows how metadata are critical for increasing confidence in the authenticity of long-term precipitation indices.

There is strong independent evidence of persistent, regional droughts in the 1850s and 1880s but bridging and homogenization techniques increase dependency between records as the network density decreases further back in time. This is particularly the case for the 1850 s where only 8 stations were active; by the 1880 s this increases to 19 . Thus, greater drought coherence would be expected at the beginning of the IIP series than at the end due to the smaller number of active stations. Hence, when evaluating the realism of Markov model simulations there is ambiguity about whether inability to replicate dry spells ( $>10$ seasons) at some sites is due to model deficiency, uncertainty in homogenized data, or both.

There is plenty of scope for developing more elaborate Markov model simulations for Ireland. For example, seasonal Pdd and Pww parameters could be conditioned by the phase of the North Atlantic Oscillation, Atlantic Multidecadal Oscillation, or El Niño Southern Oscillation to replicate low-frequency variations (evident in Figure 4) and hence more realistic clustering of dry spells at decadal time-scales (e.g. Wilby et al., 2002). The distribution of seasonal precipitation anomalies could be simulated using gamma or normal functions. There is also scope for multi-site simulation of meteorological drought occurrence and severity across the network as a whole and/or within homogeneous precipitation regions. Such tools could be used to simulate groundwater recharge, river flow and reservoir levels for vulnerable water supply zones, as well as for assessing potential environmental stress.

An important finding of our analysis is that recent decades have been relatively benign in terms of widespread, multi-year sequences of below average rainfall in Ireland. This reflects a return to generally stormier and wetter summers since the 1990s (Matthews et al., 2015). Nonetheless, there is no room for complacency about drought risk given rising water demands. Routinely updating the Pdd and Pww indices offers a simple way of tracking the long-term propensity for seasonal rainfall deficits in Ireland.

\section{Conclusions}

We have investigated the spatial and temporal properties of long-lasting negative rainfall anomalies across the Island of Ireland at site and regional scales with half-year granularity. Our aim was to create the first coherent picture of multi-season rainfall deficit occurrence and persistence across the region and, in the process, subject the IIP network to stringent appraisal. Our preliminary analysis has highlighted the immense value of carefully cataloguing station metadata - an essential resource for interpreting break-points and exceptional runs of below/above average precipitation. We acknowledge that interpretations of spatial patterns are hindered by the sparse and uneven distribution of sites, as well as by the range of issues picked up by metadata, so we were restricted to describing three types of spell-length regime. Further work is needed to determine whether these regimes form coherent clusters in space.

Overall, we find that the Island of Ireland is surprisingly prone to runs of seasonal rainfall deficiency and that major dry spells in the 1850s, 1880s and 1970s were far more persistent than any episodes experienced in the last 40 years. These events could provide useful analogues for stress testing the robustness of water supply and drought plans; a practice that is finding favour elsewhere (e.g. Spraggs et al., 2015). As Irish Water embarks on a period of major investment in water infrastructure, stress testing designs against episodes with negative rainfall anomalies lasting up to nine seasons offers an altogether different risk assessment than ability to cope with single season deficiencies. We also show that there is relatively high likelihood ( $p=0.125)$ of a continuous 5-year (10 season) dry spell at Dublin, a region in which population growth and aging infrastructure has resulted in a water system operating at the edge of its capacity.

In practice, water resource system vulnerability depends on a host of factors including the type(s) of resource (i.e. groundwater, river intake, reservoir, or combination of sources); amount of raw and treated water storage; connectivity of the system linking points of supply to demand; water quality and treatment constraints. Such issues would clearly modulate any assessment of droughts based on the analysis of meteorological data alone. Homogenized rainfall series would need to be fed into more elaborate rainfall-runoff models and then, in turn, simulated inflows input to water system models. Markov modelling, as demonstrated for IIP, offers a way of generating severe drought sequences for evaluating water supply system performance under combinations of long duration and intense rainfall deficits.

We have only begun to speculate about the underlying physical drivers of dry spells lasting 5 or even 10 years. This is an area of active research, not least because of the potential to apply such insights to long range drought forecasting (Folland et al., 2015; Kingston et al., 2015). Assembling homogeneous meteorological records from paper and digital records (with accompanying metadata) is a laborious but critical part of this process. Creation of the IIP series (Noone et al., 2015), reference networks for river flow (Murphy et al., 2013) and attendant analytical tools (Wilby et al., 2015) is bringing together ingredients needed for a deeper understanding of multi-decadal hydroclimatic variability and change at a sentinel location of Europe.

\section{Acknowledgements}

$\mathrm{SN}$ and $\mathrm{SH}$ are funded by the Irish Research Council. CM, TM and CB acknowledge funding provided by the Irish Environmental Protection Agency under project 2014-CCRP-MS.16. The authors thank the anonymous referees for their diligent and constructive remarks. 


\section{References}

Alexander LV, Jones PD. 2001. Updated precipitation series for the UK and discussion of recent extremes. Atmos. Sci. Lett. 1: 142-150, doi: 10.1006/asle.2001.0025.

Barker PA, Wilby RL, Borrows J. 2004. A 200-year precipitation index for the central English Lake District. Hydrol. Sci. J. 49: 769-785.

Barrington RM. 1888. The drought of 1887, and some of its effects on Irish agriculture. J. Stat. Soc. Inquiry Soc. Ireland IX(LXVII): 223-247.

Bastola S, Murphy C, Sweeney J. 2011. The role of hydrological modelling uncertainties in climate change impact assessments of Irish river catchments. Adv. Water Resour. 34: 562-576.

Brogan L, Cunnane C. 2005. Low flows and low flow distributions for Ireland. Understanding and managing hydrological extremes. In Irish National Committees of the IHP and ICID National Hydrology Seminar 2005, 15 November 2005, 85-92.

Burt TP, Horton BP. 2007. Inter-decadal variability in daily rainfall at Durham (UK) since the 1850s. Int. J. Climatol. 27: 945-956.

Burt TP, Howden NJK. 2011. A homogeneous daily rainfall record for the Radcliffe Observatory, Oxford, from the 1820s. Water Resour. Res. 47: W09701.

Caussinus H, Mestre O. 2004. Detection and correction of artificial shifts in climate series. J. R. Stat. Soc.: Ser. C (Appl. Stat.) 53: 405-425.

Dublin City Council. 2010. The Plan: Water Supply Project - Dublin Region. Report by RPS and Veolia Water UK, Dublin City Council, Dublin, $125 \mathrm{pp}$.

Dooge JCI. 1985. Droughts in Irish history. In Irish Rivers, de Buitléar É (ed). Country House Press: Dublin, 26-28.

Folland CK, Hannaford J, Bloomfield JP, Kendon M, Svensson C, Marchant BP, Prior J, Wallace E. 2015. Multi-annual droughts in the English Lowlands: a review of their characteristics and climate drivers in the winter half year. Hydrol. Earth Syst. Sci. 11: 12933-12985.

Garcia-Suarez AM, Butler CJ. 2006. Soil temperatures at Armagh Observatory, Northern Ireland, from 1904 to 2002. Int. J. Climatol. 26: 1075-1089.

Holden NM, Brereton AJ, Fealy T, Sweeney J. 2003. Possible change in Irish climate and its impact on barley and potato yields. Agric. For. Meteorol. 116: 181-196.

Hunt ASP, Wilby RL, Dale N, Sura K, Watkiss P. 2014. Embodied water imports to the UK under climate change. Clim. Res. 59: 89-101.

Jones PD, Lister DH, Wilby RL, Kostopoulou E. 2006. Extended river flow reconstructions for England and Wales, 1865-2002. Int. J. Climatol. 26: 219-231.

Kingston DG, Stagge JH, Tallaksen LM, Hannah DM. 2015. European-scale drought: understanding connections between atmospheric circulation and meteorological drought indices. J. Clim. 28: 505-516

MacCarthaigh M. 1996. An Assessment of the 1995 Drought Including a Comparison With Other Drought Years. Environmental Protection Agency: Dublin, 70 pp.

Mandal UK. 2011. Studies in Low and Flood Flow Estimation for Irish River Catchments. Unpublished $\mathrm{PhD}$ thesis, National University of Ireland, Galway, Ireland.

Marsh T, Cole G, Wilby RL. 2007. Major droughts in England and Wales, 1800-2006. Weather 62: 87-93.

Matthews T, Murphy C, Wilby RL, Harrigan S. 2014. Stormiest winter on record for Ireland and UK. Nat. Clim. Change 4: 738-740.

Matthews T, Murphy C, Wilby RL, Harrigan S. 2015. A cyclone climatology of the British-Irish Isles 1871-2012. Int. J. Climatol., doi: $10.1002 /$ joc. 4425 .

Mestre O, Domonkos P, Picard F, Auer I, Robin S, Lebarbier E, Böhm R, Aguilar E, Guikarro J, Vertachnik G, Klan-car M, Dubuisson B,
Stepanek P. 2013. HOMER: a homogenization software - methods and applications. Idojaras 117: 47-67.

Murphy C, Harrigan S, Hall J, Wilby RL. 2013. Assessing climate driven trends in mean- and high- river flows from a network of reference stations in Ireland. Hydrol. Sci. J. 58: 755-772.

Noone S, Murphy C, Coll J, Matthews T, Mullan D, Wilby RL, Walsh S. 2015. Homogenisation and analysis of an expanded monthly rainfall network for the Island of Ireland (1850-2010). Int. J. Climatol., (in press).

O'Laoghog SS. 1979. The dry period October 1974 to 1976. Meteorological Service, Internal Memorandum 88/79, Dublin.

Sharma TC, Panu US. 2012. Prediction of hydrological drought durations based on Markov chains: case of the Canadian prairies. Hydrol. Sci. J. 57: 705-722.

Rodda JC, Marsh TJ. 2011. The 1975-76 Drought - A Contemporary and Retrospective Review. Centre for Ecology \& Hydrology: Wallingford, CT.

Sen Z. 1980. Statistical analysis of hydrologic critical droughts. ASCE J. Hydraul. Div. 106: 99-115.

Sharma TC, Panu US. 2014a. Modeling of hydrological drought durations and magnitudes: experiences on Canadian streamflows. J. Hydrol.: Reg. Stud. 1: 92-106.

Sharma TC, Panu US. 2014b. A simplified model for predicting drought magnitudes: a case of streamflow droughts in Canadian Prairies. Water Resour. Manage. 28: 1597-1611.

Spraggs G, Peaver L, Jones P, Ede P. 2015. Re-construction of historic drought in the Anglian Region (UK) over the period 1798-2010 and the implications for water resources and drought management. J. Hydrol. 526: $231-252$.

Stead DR. 2014. Irish agriculture and agricultural policy during the hot, dry summer of 1976. Agric. Hist. Rev. 62: 337-359.

Steele-Dunne S, Lynch P, McGrath R, Semmler T, Wang S, Hanafin J, Nolan P. 2008. The impacts of climate change on hydrology in Ireland. J. Hydrol. 356: 28-45.

Sutton RT, Dong B. 2012. Atlantic Ocean influence on a shift in European climate in the 1990s. Nat. Geosci. 5: 788-792.

Symons GJ. 1887. British Rainfall. Edward Stanford: London.

Tabony, R.C. 1980. A Set of Homogeneous European Rainfall Series, Meteorological 13 Branch Memorandum No. 104, Meteorological Office, Bracknell, UK

Venema VKC, Mestre O, Aguilar E, Auer I, Guijarro JA, Domonkos P, Vertacnik G, Szentimrey T, Stepanek P, Zahradnicek P, Viarre J, Müller-Westermeier G, Lakatos M, Williams CN, Menne MJ, Lindau R, Rasol D, Rustemeier E, Kolokythas K, Marinova T, Andresen L, Acquaotta F, Fratianni S, Cheval S, Klancar M, Brunetti M, Gruber C, Prohom Duran M, Likso T, Esteban P, Brandsma T. 2012. Benchmarking homogenization algorithms for monthly data. Clim. Past 8: $89-115$.

Wilby RL. 2007. Experimental seasonal rainfall forecasts for the River Medway, UK. British Hydrological Society National Meeting on Drought Forecasting: London.

Wilby RL, Quinn NW. 2013. Reconstructing multi-decadal variations in fluvial flood risk using atmospheric circulation patterns. J. Hydrol. 487: 109-121.

Wilby RL, Conway D, Jones PD. 2002. Prospects for downscaling seasonal precipitation variability using conditioned weather generator parameters. Hydrol. Processes 16: 1215-1234.

Wilby RL, Prudhomme C, Parry S, Muchan KGL. 2015. Persistence of hydrometeorological droughts in the United Kingdom: a regional analysis of multi-season rainfall and river flow anomalies. J. Extreme Events (in press).

Wilhite DA, Glantz MH. 1985. Understanding the drought phenomenon: the role of definitions. Water Int. 10: 111-120. 